\title{
Conferência O outro do texto: o pathos na criação literária
}

Freud sempre supôs que os textos dos escritores criativos revelariam a presença dos desejos inconscientes do seu autor. A leitura de alguns desses autores nos faz também suspeitar da presença de uma força estranha que impele à escritura. $\mathrm{O}$ testemunho desses autores leva à hipótese de que a produção poética está diretamente ligada a certos motivos inconscientes, sendo o texto o resultado de uma exigência interna que força o caminho do trabalho simbólico, mesmo que este trabalho algumas vezes permaneça alienado da consciência do seu executor.

Estaríamos em muito boa companhia se tentássemos aplicar critérios psicanalíticos para a compreensão dos escritores criativos, pois o próprio Freud nos antecedeu em tarefa semelhante. Primeiro, em 1906, ao aceitar a provocação de Jung para analisar um exemplar dos sonhos "criados por escritores imaginativos e por estes atribuídos a personagens no curso de uma história". Tal desafio resultou no trabalho sobre "Delírios e sonhos na Gradiva de Jensen". Depois, em 1907, ao associar a atividade desses escritores ao devaneio ou fantasias diurnas dos adultos, derivados das atividades lúdicas infantis, em seu pequeno texto sobre "Escritores criativos e devaneios". Mais tarde, em 1919, Freud volta a se preocupar com o tema da estética ao analisar a categoria do "Estranho" (Das unheimlich), aquilo que é assustador, provocando medo ou horror. 
A abordagem linguística do termo feita por Freud nos adverte da presença desse estrangeiro que todos hospedamos dentro de nós, cujos efeitos vamos agora investigar, a partir do testemunho de alguns escritores criativos da nossa língua.

Fernando Pessoa (1965a), o primeiro a ser evocado, parece querer dialogar com Freud ao alertar, em sua Nota preliminar aos poemas de Mensagem, que "o entendimento dos símbolos e dos rituais (simbólicos) exige do intérprete que possua cinco qualidades ou condições, sem as quais os símbolos serão para ele mortos e ele morto para eles". E cita tais qualidades em ordem crescente de complexidade: Simpatia, Intuição, Inteligência e Compreensão. Sejamos solidários com as dificuldades do poeta com a quinta qualidade ou condição que não consegue ao menos nomear, alegando que esta "é menos definível. Direi, talvez, falando a uns que é a graça, falando a outros que é a mão do Superior Incógnito, falando a terceiros que é o Conhecimento e Conversação do Santo Anjo da Guarda, entendendo cada uma destas coisas que são a mesma maneira como as entendem aqueles que delas usam, falando ou escrevendo" (p. 69). E assim encerra o poeta a Nota preliminar, deixando-nos desamparados para a decifração da sua quinta condição, por mais simpáticos e intuitivos que pretendamos ser.

Mas em outra parte do livro Pessoa abre mão do seu hermetismo para nos fazer vislumbrar a contrafacção da hermenêutica, ou seja, o processo de criação simbólica. No seu caso, a criação poética. Querendo fazer uma brincadeira com seu amigo Sá Carneiro, Pessoa (1965b) procura

de inventar um poeta bucólico, de espécie complicada, e apresentar-lho, já não me lembro como, em qualquer espécie de realidade. Levei uns dias a elaborar o poeta mas nada consegui. Num dia em que finalmente desistira - foi em 8 de março de 1914 - acerquei-me de uma cômoda alta e, tomando um papel, comecei a escrever de pé, como escrevo sempre que posso. E escrevi trinta e tantos poemas a fio, numa espécie de êxtase cuja natureza não conseguirei definir. (p. 674-675)

O que se observa aqui é o aparecimento súbito de uma produção simbólica, como se esta fosse arquitetada em algum outro lugar, apresentando-se pronta à consciência do poeta. Note-se, porém, que há algo querendo ser dito, e que força sua passagem à escrita, insinuando-se primeiro na sugestão da brincadeira com o amigo Sá Carneiro. Mas é algo que não pode ser alcançado de fora para dentro. Não adianta ir buscá-lo voluntariamente. É preciso desistir e deixar que esse algo surja quando bem entender, como se tivesse vida própria. E o desconhecimento consciente atribui à surpresa um caráter epifânico:

Foi o dia triunfal de minha vida, e nunca poderei ter outro assim. Abri com um título - "O guardador de Rebanhos". E o que se seguiu foi o aparecimento de alguém em mim, a quem dei logo o nome de Alberto Caeiro. Desculpe-me o absurdo da frase: aparecera em mim o meu mestre. Foi essa a sensação que tive. (p. 675) 


\section{CONFERÊNCIA}

O mestre, o estranho interno, faz o seu raro aparecimento entre os homens. E a estranheza que causa a sua presença faz com que o ego do poeta se esforce para manter sua soberania:

(...) escritos que foram esses trinta e tantos poemas, imediatamente peguei noutro papel e escrevi, a fio, também, os seis poemas que constituem a "Chave oblíqua", de Fernando Pessoa. Imediatamente e totalmente (...) Foi o regresso de Fernando Pessoa Alberto Caeiro a Fernando Pessoa ele só. Ou melhor, foi a reação de Fernando Pessoa contra a sua inexistência como Alberto Caeiro. (p. 675)

E não se diga que esta explicação epifânica se deva à ingenuidade de um poeta ligado à tradição rosacruz. Fernando Pessoa sabe do que está falando:

Começo pela parte psiquiátrica. A origem dos meus heterônimos é o fundo traço de histeria que existe em mim. Não sei se sou simplesmente histérico, se sou, mais propriamente, histero-neurastênico. Tendo para esta segunda hipótese, porque há em mim fenômenos de abulia que a histeria, propriamente dita, não enquadra no registro dos seus sintomas. (p. 673)

Embora seja louvável que o poeta tenha ido atrás de uma explicação científica que o ajudasse a compreender o seu processo criativo, não deixa de ser lamentável que Pessoa, já em 1935, ainda desconhecesse os esforços de Freud, desde 1894, para dissertar com clareza "Sobre os critérios para destacar da neurastenia uma síndrome particular intitulada neurose de angústia". De outra forma, saberia que "assim como um ataque de vertigem pode ser substituído por um desmaio, a vertigem crônica pode ser substituída por um sentimento permanente de grande fraqueza, lassidão e assim por diante" (p. 116). O parentesco da abolia de Pessoa com a histeria é muito mais estreito do que imagina, pois têm ambas como fonte comum a incidência da sexualidade sobre o seu tênue corpo de poeta. Mas isto não estraga o seu ponto de vista, pois

Seja como for, a origem mental dos meus heterônimos está na minha tendência orgânica constante para a despersonalização e para a simulação. Estes fenômenos — felizmente para mim e para os outros — mentalizaram-se em mim; quero dizer, não se manifestam na minha vida prática, exterior e de contato com os outros; fazem explosão para dentro e vivo-os eu a sós comigo. Se eu fosse mulher - na mulher os fenômenos histéricos rompem em ataques e coisas parecidas - cada poema de Álvaro de Campos (o mais histericamente histérico em mim) seria um alarme para a vizinhança. Mas sou homem - e nos homens a histeria assume principalmente aspectos mentais; assim, tudo acaba em silêncio e poesia. (Pessoa, 1965, p. 673-674)

A nosso ver, o que o poeta faz com a sua indexação patológica é determinar a modalidade da sua via de acesso a essa produção simbólica que jorra como se fosse de outro. O que permanece obscuro é a forma como uma certa excitação sexual 
somática, que estaria, segundo Freud, na base do mecanismo da angústia, consegue se expressar numa linguagem poética sofisticada, o que requer, por princípio, um complexo trabalho de transformação.

Deixemos em paz a Nação poética de Lisboa e atravessemos de volta o Atlântico em busca de luzes tupiniquins. Recuemos um pouco até dezembro de 1921 para encontrar Mário de Andrade dedicando a Paulicea Desvairada ${ }^{1}$ ao seu Mestre Querido, cujo nome destaca em maiúsculas: MÁRIO DE ANDRADE. A esse misterioso homônimo, a quem oferta "este livro que de vós me veio", o escritor pede que receba

No vosso perdão o esforço do escolhido por vós par único discípulo; daquele que neste momento de martírio muito a medo inda vos chama o seu Guia, o seu Mestre, o seu Senhor. (Andrade, 1987, p. 58)

Fica difícil descobrir as intenções do autor com tal dedicatória, pois ele mesmo, mais adiante, no Prefácio interessantíssimo, nos adverte que é "muito difícil nesta prosa saber onde termina a blague, onde principia a seriedade. Nem eu sei” (p. 60). Assim, cabe a nós rastrear esse prefácio, de fato interessantíssimo, para no seu curso distinguir a blague da seriedade, com o intuito de saber se, além do alaúde, o Tupi Caixa d'Óculos também se servia de instrumentos esotéricos em seu processo de criação.

Em mais de um lugar Mário de Andrade deixou dito que o seu processo de criação se compunha de dois momentos. No primeiro, ao qual chamava momento de poesia, deixava que todas as ideias brotassem abruptamente, anotando-as tais como se apresentavam à sua consciência. Foi assim que, numa única noite, surgiram todas as ideias presentes em Paulicea desvairada. O segundo momento, que ele chama de trabalho de arte, é quando o intelectual rigoroso dá forma e unidade ao que antes fora produzido desordenadamente. A própria razão para escrever o Prefácio deve-se a que, nos diz Mário, "quando sinto a impulsão lírica, escrevo sem pensar tudo o que meu inconsciente me grita. Penso depois: não só para corrigir, como para justificar o que escrevi" (p. 59). A presença aqui do termo inconsciente já fornece uma pista valiosa aos nossos propósitos. Mário de Andrade lera Freud, provavelmente em alemão. E ao longo do Prefácio vai nos mostrar que a leitura não foi em vão.

A sua compreensão da divisão tópica e da diferença entre os dois princípios de funcionamento mental se revela ao constatar "que si na minha poesia a gramática às vezes é desprezada, graves insultos não sofre neste prefácio interessantíssimo. Prefácio, rojão do meu eu superior. Versos: paisagem do meu eu profundo” (p. 73).

${ }^{1}$ Grafada assim na capa da edição original de 1922. 


\section{CONFERÊNCIA}

E o domínio dos termos freudianos vai ajudar o intelectual a entender melhor o seu processo de criação:

Dom Lirismo, ao desembarcar do Eldorado do Inconsciente, no cais da terra do Consciente, é inspecionado pela visita médica, a inteligência, que o limpa dos macaquinhos e de toda e qualquer doença que possa espalhar confusão, obscuridade na terrinha progressista. Dom lirismo sofre mais uma visita alfandegária, descoberta por Freud, que a denominou Censura. (p. 73)

A tomada de consciência de que uma outra autoridade, além da inteligência, interfere na produção poética, impedindo que uma parte do material inconsciente se torne consciente, vai fazer com que Mário de Andrade tome precauções para garantir que um volume maior de produção passe de uma instância a outra. Como ele mesmo confessa, "sou contrabandista e contrário à lei da vacina obrigatória" (p. 73). Mas o seu espírito de contraventor sabe que há um preço a pagar:

Parece que sou todo instinto (...) Não é verdade. Há no meu livro, e não me desagrada, tendência pronunciadamente intelectualista. Que quer você? Consigo passar minhas sedas sem pagar direitos. Mas é psicologicamente impossível livrar-me das injeções e dos tônicos. (p. 73)

O tom intelectualista é o resultado da solução de compromisso entre o "instinto" e a censura. Para que passem as sedas, é preciso revesti-las de uma linguagem de disfarce. É preciso uma longa perlaboração para que pareça "instinto" o que "instinto" foi em sua origem. E todo esse trabalho é feito por meio da construção de uma linguagem o mais próximo possível da produção inconsciente, "pois acontece que meu inconsciente não sabe da existência de gramáticas, nem de línguas organizadas. E como Dom Lirismo é contrabandista..." (p. 73) consegue contrabandear para a linguagem consciente a retórica desordenada das pulsões que, olhadas à distância, revelariam uma outra ordem de significação:

O impulso clama dentro de nós como turba enfurecida. Seria engraçadíssimo que a esta se dissesse: "Alto lá! Cada qual berre por sua vez; e quem tiver o argumento mais forte, guarde-o para o fim!” A turba é confusão aparente. Quem souber afastar-se idealmente dela, verá o imponente desenvolver-se dessa alma coletiva, falando a retórica exata das reivindicações. (p. 67)

Em determinado momento, o poeta reconhece claramente a prioridade das emoções que subjazem ao discurso secundário, pois o seu prefácio, "com todo o disparate das teorias que contém, não vale coisíssima nenhuma. Quando escrevi Paulicéia desvairada não pensei em nada disto. Garanto porém que chorei, que cantei, que berrei... Eu vivo!" (p. 67). E todo o seu trabalho de arte vai ter como finalidade deixar transparecer essa emoção para um leitor que se quer participante, onde irão se reproduzir as experiências originárias do autor, pois, 
“aliás, versos não se escrevem para leitura de mudos. Versos cantam-se, urram-se, choram-se" (p. 67).

Por fim, o leitor arguto de $A$ interpretação de sonhos nos dá boa prova do quanto lhe valeu o contato com a obra freudiana. Mesmo que o uso do termo subconsciente denuncie restos de antigas leituras psiquiátricas, o conceito e a prática da livre-associação mostram-se presentes na afirmação de que "quem canta seu subconsciente seguirá a ordem imprevista das comoções, das associações de imagens, dos contatos exteriores. Acontece que o tema às vezes descaminha" ( $p$. 66-67). E o desencaminhamento dos temas leva o poeta à perplexidade frente a certos enigmas propostos pelo seu inconsciente, a exemplo de Espelho, Pirineus, Caiçaras:

Esta é uma das cinco expressões nascidas mais espontaneamente em mim, e das que mais deslumbraram (...) Nunca pude saber o sentido exato dessas palavras, mas elas porém ficaram em mim como um refrão do significado íntimo do meu ser. (p. 47)

Mas o psicanalista aprendiz logo domina a técnica da autoanálise, indo, no rastro do exemplo freudiano, em busca do sentido que se esquiva à compreensão imediata. Logo acha uma explicação plausível para Pirineus e Caiçara, que se apresentavam como uma antítese: "a pesquisa violenta, exacerbada, voluntária do Brasil, explodindo num brasileirismo violento 'caiçara' e a minha mania de estudar, de me cultivar, que me fazia tão livre, tão longíncuo do Brasil, fulgindo na palavra Pirineus” (p. 47).

$\mathrm{O}$ par antitético de palavras pode, como quer num primeiro tempo o poeta, expressar "essa angústia desnacionalizante da cultura", mas pode também ser tomado como expressão de uma outra angústia, resultado de outra desnacionalização. O seu conhecido pudor, somado a um outro punhado de resistência, pode estar impedindo o poeta, assim como o fazia a Freud, de revelar certas representações investidas de sexualidade presentes no processo associativo. Mas isto não tira o valor do trabalho nem desqualifica os resultados alcançados. Mário de Andrade revela que não sentia amor pela palavra caiçara, pois desconfiava que tinha se inserido na expressão a partir da necessidade técnica de quebrar a continuidade do verso que vinha muito escuro, em sons de ês fechados. Pirineus, pelo contrário, agradava muito ao poeta. Mesmo sem ser procurada nem compreendida no momento em que explodiu, é a única palavra sobre cujo sentido não tinha dúvidas: "É o trampolim do salto brasileiro - (...) eram mesmo os Pirineus que me pulavam pra outras culturas e pro que fizera o meu espírito e o sentido individualista do meu ser" (p. 47).

Agora, a antítese entre Caiçara e Pirineus vem se condensar nesta última palavra, revelando um conflito que presidiu toda a vida intelectual do autor, com graves ressonâncias em sua personalidade total. E a análise prossegue, 


\section{CONFERÊNCIA}

atingindo regiões cada vez mais nucleares. Mas isso não se dá sem a manifestação indispensável da resistência, que se materializa na palavra espelhos: "Juro que jamais consegui lhe penetrar o sentido, embora eu a sentisse verdadeira, impossível de mudar. Deixei, 'sentia' a palavra, mas quando refletia sobre ela e seu possível valor, ficava irritado, até mesmo desgostoso" (p. 47).

O duro enigma resistia à decifração, ao mesmo tempo em que impunha sua força significante. Só depois de publicado o poema em que surgiram as estranhas palavras, quando, em dezembro de 1941, Mário rabiscava uma contribuição para um livro de um amigo,

saiu no corrente esta frase: "Pois então vamos premiar essa felicidade (a minha) ajudando com minhas posses a sociedade humana a se viver, decidi no espelho". Nem bem escrevi isso, tive um deslumbramento tamanho que até estremeci. A coisa viera enfim à consciência, o sentido de "espelhos" do meu verso! (p. 48)

Eis a surpresa luminosa da revelação de um sentido até então inconsciente. Agora o caminho está livre para novas associações:

Toda minha vida tive uma preocupação danada de combater a vaidade; que considero epidérmica e mesquinha, e convertê-la em orgulho, que é fecundo, viril, capaz. O que não impede que eu tenha minhas vaidades, está claro, embora combatidas e desprezadas. (p. 48)

Agora, uma antinomia mais radical vem à tona: vaidade $x$ orgulho, feminino $x$ masculino lutam pela posse narcísica daquele que se refletia. E esta organização narcísica logo se torna em ideal do ego, pois 'O 'espelho' mirado me indicava a postura do retrato que queria tornar. Se é certo que nunca estudei atitudes no espelho, não é menos certo que muitas vezes me surpreendi me contemplando, me observando no espelho, e me retirava envergonhado" (p. 48). Vergonha narcísica, vergonha da atitude narcísica, vergonha da vaidade feminina que se olha, vergonha do reflexo feminino que se vê. Vergonha como força repulsiva da contemplação autoerótica que impele para o amor (viril) dos objetos. E a fragmentação, a fusão identificatória e os rudimentos do sujeito podem todos ser vislumbrados no texto inspirado do poeta:

"Espelhos" no verso não tem dúvida que tem sentido complexo, mas puramente individualista. Sou eu, é minha vaidade, é minha conversão, melhor, abatimento das vaidades procurando ter orgulho de mim, é a externidade das minhas atitudes voluntariosas, são minhas aventuras e experiências estéticas, artísticas, vitais. É o ser visto pelo espelho. Não sou eu integralmente, mas o meu eu invisível em espelhos. Até por mim (...) (p. 48)

Aí está o momento supremo da análise. O que antes era enigma, explode agora em significações. O condensado se entrega à decomposição, mostrando os múltiplos sentidos guardados em suas entranhas. E assombra a nós, leitores, como tudo isto 
já estava previsto no poema Eu sou trezentos... escrito em junho de 1929, em que as três palavras irromperam: "Só o esquecimento é que condensa." Condensa e desloca, teria dito Freud. E o final da análise apenas aquieta, não permitindo nenhuma outra alegria além da satisfação restrita ao gosto do enigma decifrado: "Por onde percebo agora que esse verso é terrivelmente doloroso. Já não 'sofria' propriamente com ele, mas não é que o achasse bonito ou belo: ele me deslumbra feito uma definição. E a definição acabava chegando!" (p. 48). Esta definição também já estava prevista no poema onde, em meio à experiência desagregadora de ser trezentos, trezentos e cincoenta, o poeta já vislumbra a esperança do descanso: "Mas um dia afinal eu toparei comigo (...)".

Assim, assistimos, vinte anos depois, realizar-se o encontro do qual o autor se gabava no Prefácio interessantíssimo de 1921: "Por muitos anos procurei-me a mim mesmo. Achei. Agora não me digam que ando à procura de originalidade, porque já descobri onde ela estava, pertence-me, é minha” (p. 75). Ainda não era verdade. Somente agora, depois do espelho, Mário de Andrade podia encarar de frente o mistério do seu Mestre MÁRIO DE ANDRADE.

A partir dos dois autores visitados, vimos que a produção poética está diretamente ligada a certos motivos inconscientes e que um texto é sempre o resultado de um tipo interno de exigência que força o caminho para o trabalho simbólico, mesmo que às vezes tal trabalho permaneça alienado da consciência do seu executor. Podemos invocar ainda um outro testemunho desse tipo de exigência que é capaz de pôr um cético contumaz como Paulo Francis (1990) a duvidar de uma de suas mais sólidas convicções, durante um mês e meio em que começou a escrever um romance pelo motivo bastante trivial de ter recebido há mais de um ano um adiantamento do editor:

Esqueci por completo meu dia a dia, minha mortalidade, minhas broncas inenarráveis, pois, como na infância, nossa solidão é total. (...) Mas foi um jorro inestancável (...) eu precisava de três computadores para me conter. (...) Uma das poucas certezas, minha descrença no sobrenatural, está abalada. Quando me sentei onde estou agora e comecei a escrever, tinha duas ideias (...) Não é exagero dizer que o livro se escreveu. Ao fim de cada dia, ou noite, eu olhava pasmo a tela do computador, puxando para cima e para baixo, chegando a duvidar que aquilo fosse meu. Certamente não tinha a intenção de escrever o que escrevi. Veio não sei de onde. Se impôs, irresistivelmente (...). Nada premeditado, juro. Se escreveu por si próprio. E os personagens me importunavam o tempo todo. Quando eu não estava em outro trabalho me cobravam crescimento e participação, às vezes obsessivamente. E importunam ainda. (...) Isto é só meu inconsciente? Não tem relação visível comigo. Será energia psíquica dispersa no universo? Procuro explicações racionais.

É de se esperar que essa espécie de força demoníaca, que impele o escritor a uma produção simbólica da qual ele não se sente senhor, venha a se refletir no 


\section{CONFERÊNCIA}

próprio texto que, enfim, ele produziu. Ainda está para ser desenvolvido algum método de análise capaz de detectar a presença dessa força e, mais ainda, revelar as intenções de sentido que porventura se insinuem em certos movimentos do texto. Qualquer que seja a natureza desse método, analítico ou hermenêutico, ele terá de levar em conta a presença, no interior do escritor, de algo totalmente outro do seu ego. Um estrangeiro que cada um de nós carrega dentro de si, exigindo, às vezes de forma aterrorizadora, o seu direito de participar do diálogo entre as consciências.

\section{Referências}

Andrade, M. de (1987). Poesias completas. São Paulo: Edusp.

Francis, P. (1990). Monólogo interior. Folha de S. Paulo, 30.8.1990.

Freud, S. (1977). Sobre os critérios para destacar da neurastenia uma síndrome particular intitulada neurose de angústia. In Edição Standard Brasileira das Obras Psicológicas Completas de Sigmund Freud (Vol. III, p. 116). Rio de Janeiro: Imago. (Trabalho original publicado em 1895[1894]).

Freud, S. (1996). Delírios e sonhos na Gradiva de Jensen. In Edição Standard Brasileira das Obras Psicológicas Completas de Sigmund Freud (Vol. IX, p. 17). Rio de Janeiro: Imago. (Trabalho original publicado em 1907[1906]).

Pessoa, F. (1965a). Nota preliminar a Mensagem. In Obra poética. Rio de Janeiro: Aguilar.

Pessoa, F. (1965b). Notas e variantes. In Obra poética. Rio de Janeiro: Aguilar.

\section{Ronaldo Monte de Almeida}

Coordenador do Labore - Laboratório de Pesquisa em Psicopatologia do EPSI - Espaço Psicanalítico, João Pessoa, PB.

R. Nervinha Cavalcante, 46 - Miramar

58043-000 João Pessoa, PB, Br

e-mail: rona.monte@uol.com.br 